the second World War research production dropped in the 1940 s to 27 papers but publication rebounded in the 1950s with 62 papers. This marked the initiation of the intensive studies of anolis lizards by Ernst Williams and his students and of the total herpetofauna by Albert Schwartz. Thereafter, the increase has been steady with every succeeding decade and reached 697 in the 2000s.

The major portion of the book, 385 pages, presents individual accounts for 197 species of frogs and 539 reptiles (364 lizards, 17 amphisbaenians, 145 snakes. 8 turtles, and 3 crocodilians). These represent 8 families of frogs, 11 of lizards, 2 of amphisbaenids, 8 of snakes, 3 of turtles and 2 of crocodilians. Most West Indian species are unique, $99 \%$ of the frogs and $93 \%$ of the reptiles are endemic. Included in the totals are both the native and established (reproducing) introduced species. Omitted are introduced species which have not sustained an initial presence and those only recorded once which are presumed to be incidental waifs. These accounts completely omit traditional description and identification discussions to concentrate on tight summaries of published natural history. Major topics are covered under boldface headings for easy finding. These include distribution and habitat, and often abundance, activity, behavior, reproduction, prasites, size and conservation status. These accounts are backed up by an 80-page Literature Cited section containing over 2600 references from which information was extracted.

Both serious naturalists and researchers living in, or visiting, the West Indies will find this encyclopaedic natural history an indispensable reference to the published research. The more casual or anyone needing descriptions for identification will still have to depend on the 1991 Amphibians and Reptiles of the West Indies: Descriptions, Distributions and Natural History by Albert Schwartz and Robert W. Henderson (University of Florida Press, Gainesville) or wait for the field guide in preparation by Blair Hedges.

FRANCIS R. COOK

Researcher Emeritus, Canadian Museum of Nature. Ottawa, Ontario K1P 6P4 Canada

\title{
The Rise of Amphibians: 365 Million Years of Evolution
}

By Robert Carroll. 2009. John Hopkins University Press, Baltimore, Maryland USA. xii + 360 pages.

The big event in our past prehistory was the challenge met by early aquatic fish-like vertebrates of colonizing the land, already populated by tempting and doubtless abundant invertebrate prey. A bonus to be gained was an escape from the increasingly crowded conditions in the adjoining water. But the later evolved often spectacularly sized dinosaurs have gained the largest share of public interest particularly from younger audiences. Since the extinction and replacement of the once-dominant larger amphibians, the group has survived, still surprisingly diverse and numerous as much smaller forms. Here, however, we are taken back to their initial ancestral appearance and long dominance.

Robert Carroll has long been synonymous with vertebrate evolution studies at Redpath Museum, McGill University. He came with an impeccable background as a Ph.D. graduate from Harvard University, a student of the legendary icon in palaeontology, Alfred Sherwood Romer. During his tenure he has, in turn, mentored a stream of diverse PhD graduate students. Some of these have came to the Canadian Museum of Nature for various periods, notably Michael Caldwell (origins of snakes) Robert Holms (dinosaurs), and Alison Murray (fish), all moving later to fossil-rich Alberta, and Xiao-chun Wu (crocodilians) who has stayed.

This book fills a long-standing gap in texts. In 16 chapters it covers the first tentative emergence to the land. It follows amphibian diversification and dominance to a mass extinction 250 million years ago. It then covers the eventual vertebrate recovery and the amphibian replacements that evolved from the surviving stock. It concludes with the success of modern amphibians followed by speculation on the future of amphibians contributed by Caroll's successor as Director of Redpath Museum, modern herpetologist David Green. The ex-COSEWIC chair who, though admitting that there are current declines and even disappearance of some species, emphasizes that the group has survived many environmental past disasters and rebounded. It may even do better through the current humaninduced one than us humans ourselves.

Fossil history is detailed by over 200 black-andwhite illustrations of fossil skeletons of forms a often given only cursory coverage in many popular evolution texts in their haste to get to the time of the dinosaurs. A spectacular special color section is inserted between chapters 6 and 7. It contains 16 plates illustrating conceptions of the major extinct forms and concludes with examples from surviving groups: frogs, salamanders and caecilians.

Anyone interested in the early prehistory of vertebrates (and that should be all of us) should read this book. Its emphasis on the oft-neglected steps on the evolutionary ladder between fish and fish-like groups and the succeeding later vertebrates bring a treasure of detail largely long buried in obscure (to the majority of naturalists) scientific journals. We would not be here today without the benefits of the amphibian ancestral contribution.

Francis R. COOK

Researcher Emeritus, Canadian Museum of Nature, Ottawa, Ontario K1P 6P4 Canada 